\title{
Narrativas de la reconversión. Historias de vida, memoria social y acción colectiva en el astillero de Puerto Real ${ }^{1}$
}

\author{
Narratives of the Restructuring. Life Histories, Social \\ Memory and Collective Action at Puerto Real Shipyard
}

\author{
Beltrán Roca \\ Universidad de Sevilla, España \\ David Florido del Corral \\ Universidad de Sevilla, España
}

\section{RESUMEN}

Este artículo analiza la memoria colectiva de las protestas contra la reconversión naval a través de las historias de vida de dos sindicalistas de las centrales CCOO y CNT en el astillero de Puerto Real (Cádiz). Los relatos de los sindicalistas se centraran en las experiencias de movilización contra el segundo periodo de reconversión del sector de la construcción naval (que tuvieron lugar en Puerto Real entre 1986 y 1987). Se ha seleccionado este episodio de las protestas por ser uno de los de mayor radicalidad, innovación y proyección social. Las historias de vida nos permitirán estudiar el papel de la memoria social en la acción colectiva y analizar el disputado terreno del sindicalismo en España durante la transición y la consolidación del régimen democrático.

Palabras clave: Sindicalismo; Reconversión industrial; Acción colectiva; Memoria social; Historia de vida; Andalucía.

\section{SUMMARY}

This article explores the collective memory of the protests against the restructuring of the shipbuilding industry through the life histories of two organisers of the Spanish trade unions CCOO and CNT at Puerto Real shipyard. The unionists' narratives focus on mobilization experiences against the second stage of the industrial restructuring (which took place in Puerto Real between 1986 and 1987). This episode has been chosen for its radicalism, innovation and social impact. Their life histories are used to study the role of social memory in collective action and to analyse the disputed terrain of trade unionism in Spain during the political transition and the consolidation of the democratic regime.

Key words: Trade Unionism; Industrial Restructuring; Collective Action; Social Memory; Life Histories; Andalusia.

\footnotetext{
${ }^{1}$ Este trabajo es resultado de un proyecto de investigación sobre las movilizaciones contra la reconversión en el astillero de Puerto Real llevado a cabo en 2008. El proyecto se titula "Reconversión naval, sindicalismo y protesta popular en el astillero de Puerto Real", código PRY14/ 08 y ha sido financiado por la Fundación Centro de Estudios Andaluces, de la Consejería de la Presidencia de la Junta de Andalucía. En esta investigación se empleó una metodología cualitativa: se utilizaron fuentes documentales y hemerográficas y testimonios orales obtenidos mediante 25 entrevistas semi-estructuradas a trabajadores y agentes sindicales.
} 


\section{INTRODUCCIÓN}

En 2011, cuando las movilizaciones del 15M llegaron a Puerto Real y los indignados $^{2}$ organizaron asambleas en la céntrica Plaza de Jesús, los ciudadanos de esta ciudad-fábrica tuvieron una especie de déjà $v u$. Periódicamente, en cada oleada de reconversión del sector naval, los trabajadores del astillero del municipio de la Bahía de Cádiz, del que ha dependido históricamente buena parte de la economía local, organizan asambleas para informar y movilizar a los ciudadanos para defender el mantenimiento de los cada vez más escasos puestos de trabajo que van quedando en esta industria. Especialmente durante la segunda reconversión, en los años 1986 y 1987, la Plaza de Jesús y otros enclaves de Puerto Real fueron escenario de asambleas, barricadas y enfrentamientos con las fuerzas de seguridad del estado (Florido, Roca y Gutiérrez 2009 y 2013; Pérez de Guzmán 2012). Al igual que las esposas de los trabajadores del astillero en 1987, en 2006, cuando se iniciaron las movilizaciones contra la deslocalización de la planta de la multinacional Delphi en Puerto Real, las esposas de los empleados se auto-organizaron en "asambleas de mujeres" para apoyar a sus maridos en la defensa del trabajo, de sus economías domésticas, pero también de su identidad social.

Desde nuestro punto de vista, las diversas aproximaciones teóricas sobre los movimientos sociales no han prestado suficiente atención al papel de la memoria social en la configuración de la acción colectiva. El objetivo del artículo es precisamente analizar la memoria colectiva de la lucha contra la reconversión a través de las historias de vida de dos sindicalistas del astillero de Puerto Real. Los relatos de los sindicalistas se focalizarán en las experiencias de movilización contra el segundo periodo de reconversión del sector de la construcción naval (entre 1986 y 1987), por ser éstos los de mayor radicalidad, innovación y dimensión social (Florido, Roca y Gutiérrez 2013). Se han seleccionado dos relatos de los 25 recogidos en entrevistas en profundidad porque eran los que mejor reflejaban el desarrollo de la acción colectiva y las diferentes opciones sindicales presentes en la factoría: Comisiones Obreras (CCOO) y Confederación Nacional del Trabajo $(\mathrm{CNT})^{3}$.

La historia de vida puede definirse como "cualquier relato retrospectivo de un individuo sobre su vida completa o en parte, de forma escrita u oral, que ha sido obtenida o solicitada por otra persona" (Watson y Watson-Franke 1985: 2). En la historia de las ciencias sociales su uso ha pasado por diferentes momentos, desde el ostracismo por la hegemonía de paradigmas positivistas en la década de los cincuen-

\footnotetext{
${ }^{2}$ El 15M o movimiento de los indignados es un movimiento social que surge en España en mayo de 2011 en protesta por la falta de democracia y la situación económica deteriorada del país (Castells 2012).

3 Dejamos a un lado por cuestiones de espacio a los sindicatos Unión General de Trabajadores (UGT) y Colectivo Autónomo de Trabajadores (CAT) también presentes en el astillero. Esta última organización, sólo presente en Puerto Real, es una escisión de la Unión Sindical Obrera (USO) a mediados de 1970 por diferencias con los dirigentes de aquella época. Aunque UGT y CAT mantienen diferencias respecto a CCOO, las tres centrales formaron parte del Comité de Empresa, y llevaron con frecuencia una misma línea de actuación, mientras que el sindicato CNT desarrolló su actividad sindical deliberadamente al margen de dicho órgano de representación y apostó por la radicalización de la acción colectiva.
} 
ta del siglo veinte hasta su reemergencia a partir de la década de los ochenta del mismo siglo (Plummer 1983; Pujadas 1992), en lo que atinadamente Jesús Ibañez (1998) denominó el regreso del sujeto.

Siguiendo a Lewis (2008), la historia de vida tiene varias ventajas: a) permite conjugar la profundidad histórica con el detalle etnográfico; b) conecta acción y estructura —uno de los grandes retos de la sociología contemporánea (Giddens 1984)—; c) humaniza la investigación social (Plummer 1983); y d) ofrece la posibilidad de cuestionar saberes recibidos dando voz a experiencias y conocimientos subalternos. Así, esta técnica ha sido utilizada en diferentes ámbitos con el objeto de rescatar el "discurso oculto" (Scott 2004) y "empoderar" grupos subordinados. Sobre todo, interesa destacar que el enfoque biográfico permite adentrarnos en los planteamientos de los actores, tanto a nivel individual y colectivo, y contemplar la congruencia entre el decir y el hacer, y en la diversidad de perspectivas, expectativas y lecturas que los hechos sociales pueden generar, a nivel micro. Algunos de los campos de aplicación de la historia de vida son las relaciones laborales, la investigación feminista, la investigación-acción en trabajo y educación social, la investigación médica o la política social.

Las historias de vida tienen un enorme potencial tanto para el estudio de los procesos de acción colectiva como para el análisis de las relaciones laborales. Esta técnica consiste en mucho más que una mera recopilación de hechos individuales, aislados, pues los relatos de los informantes reflejan a la vez que construyen las dialécticas relaciones de poder y verdades en disputa dentro del conjunto de la sociedad. En nuestro caso, vamos a ofrecer distintos relatos de actores que vivieron la reconversión naval desde distintas agencias sindicales, en lo que podríamos denominar la técnica de relatos de vida $\operatorname{cruzados}^{4}$ (Pujadas 1992).

\subsection{El SENTIDO DE LA RECONVERSIÓN NAVAL Y LA DISPUTADA ARENA DEL SINDICALISMO}

La reconversión naval significó un cambio del horizonte histórico español. Formó parte de un reajuste del orden económico mundial. El del tránsito del modelo económico industrial al postindustrial. Un paso que afectó de pleno a la organización del trabajo (Cohen 2007) y que sustituyó el sistema de ordenación científica (taylorismo) por un nuevo modo caracterizado por la flexibilidad y la adaptabilidad a la demanda. En el caso español se produjo a través de dos grandes procesos: los cambios políticos, económicos y sociales ocurridos tras la muerte del general Francisco Franco (1892-1975) y las negociaciones para la entrada del país en la Comunidad Económica Europea. El primero significó la remodelación del marco político e institucional, incluyendo la organización y actuación de los sindicatos. El segundo representó la inmersión de España en dinámicas económicas de gran alcance, como la transformación del modelo productivo desarrollista tardo-franquista en uno nuevo definido por la terciarización de actividades, capitales y trabajo. En él, el turismo, los servicios aso-

\footnotetext{
${ }^{4}$ Es decir, relatos que convergen en un escenario común, de modo que constituyen un relato polifónico, no necesariamente convergente, que muestran la diversidad y riqueza de perspectivas sobre un episodio o un proceso social.
} 
ciados y la industria inmobiliaria eran los factores más importantes (Moreno 2002; Delgado 2012).

Así fueron marginándose diferentes actividades productivas. Entre ellas la construcción naval, que había sido impulsada por el proyecto de industrialización franquista, aunque hundía sus raíces históricas en la zona de estudio desde el siglo XVIII, en el marco de la denominada Marina Ilustrada (Martínez Romero 1991). Éste fue el escenario de la reconversión que afectó a la Bahía de Cádiz, primero al astillero de Cádiz y después al de Puerto Real. Fueron las administraciones de la naciente democracia formal española las que acometieron la transformación que conllevaba la destrucción de tejido industrial y mercados de trabajo. Una de sus principales misiones fue canalizar la tensión social y administrar la crisis social.

En este contexto de crisis multidimensional los sindicatos tuvieron un papel relevante. En el caso de estudio, como reflejo de lo que ocurría en términos generales, estamos hablando de organizaciones que tenían distintos orígenes, planteamientos ideológicos y metodologías de acción. Por un lado estaban las denominadas luchas autónomas iniciadas en los años setenta, durante el ocaso franquista (Espai en Blanc 2008). Era un movimiento político y sindical de carácter auto-organizado. Sus huelgas y movilizaciones, con un escaso o nulo contacto con organizaciones políticas y sindicatos que todavía eran ilegales, tenían una doble vertiente antifranquista y anticapitalista. Es decir, perseguían tanto reivindicaciones laborales como políticas (Torres 1998). De otro, se situaban las que terminarían siendo grandes organizaciones sindicales, con una orientación pactista y en el que predominan las estructuras centralizadas de los Comités de Empresa (Ventura 2004).

El proceso de lucha obrera de Puerto Real se movió en una posición intermedia entre el sindicalismo de concertación y las luchas autónomas. El modelo sindical de concertación estaba representado en el astillero por CCOO y UGT. Sin embargo existían otros dos sindicatos con una importante influencia: el Colectivo Autónomo de Trabajadores (CAT) y la Confederación Nacional del Trabajo (CNT). El primero se ajustaba, en términos generales, al modelo de los sindicatos mayoritarios. Por lo que fue la organización CNT la principal responsable de que la resistencia obrera en Puerto Real cobrara tintes autónomos y anarcosindicalistas. Este sindicato rechazaba de raíz el sistema sindical hegemónico y promovía asambleas como órganos soberanos. Así desarrollaron entre los trabajadores la acción directa, la democracia de base y el asamblearismo (Ibáñez 2007). Las memorias analizadas en este artículo reflejan la disputa entre estas diferentes formas de entender el sindicalismo y la acción colectiva.

\section{MEMORIA SOCIAL Y ACCIÓN COLECTIVA}

Diversas teorías han puesto de relieve distintas dimensiones de la protesta social y la acción colectiva: la estructura de oportunidades políticas que favorece la movilización social (Tarrow 1998), la capacidad organizativa para movilizar recursos y la capacidad para crear nuevas normas y sociabilidades (McAdam 1994; Melucci 1994). Sin embargo, pocos estudios han explorado cómo la memoria compartida contribuye a configurar los repertorios de acción colectiva, los imaginarios y los marcos de referencia empleados por los movimientos sociales. 
La perspectiva de la estructura de las oportunidades políticas propone centrarse en los cambios en el contexto político que hacen posible los fenómenos de protesta. Para Tarrow (1998), por ejemplo, existen dos bloques de oportunidades políticas: los elementos estables (entre los que destaca la forma de Estado) y los elementos variables (el grado de apertura del sistema político, los cambios en las alianzas de los sectores dominantes, la existencia de aliados influyentes y el conflicto entre las élites). Las organizaciones persiguen finalidades políticas, movilizando apoyos, desplegando estrategias y organizando las actividades. Habida cuenta del contexto en el que se enmarcan los movimientos de protesta que analizamos aquí, es evidente que se daban condiciones apropiadas para el surgimiento de las acciones de reivindicación: tanto por la política de reestructuración industrial, como sobre todo por la irrupción democrática, proceso en el que movimientos sociales de distinta índole ensayaban sus estrategias y expresaban sus objetivos.

Sin embargo, hemos de tener en cuenta una tercera perspectiva teórico-metodológica para clarificar nuestro análisis. Esta corriente, surgida a partir de los años ochenta del siglo pasado, recoge aportaciones de enfoques anteriores, pero enfatiza la dimensión cultural de la acción colectiva. Bajo el nombre de teoría del enmarcamiento o frame análisis (Johnston y Noakes 2005), estos autores ponen el acento en cómo los movimientos generan sus propios marcos de referencia, es decir, «ideologías, identidades colectivas, rutinas de comportamiento y culturas materiales" (McAdam 1994: 54). El objetivo de esta aproximación es comprender los marcos interpretativos construidos por los participantes de los movimientos sociales para legitimar y llevar a cabo la acción colectiva, poniendo de manifiesto el entronque entre las reivindicaciones concretas y el marco de referencia cultural en el que aquellas cobran pleno sentido, facilitando su difusión y el desenvolvimiento de formas de acción colectiva. Partimos del supuesto que el marco cultural aludido, en el doble sentido de culminación del franquismo y puesta en marcha de un nuevo horizonte político, social y cultural, constituía un contexto apropiado para el desarrollo de discursos que alimentaran los movimientos sociales, que sirvieran de marco para su difusión, especialmente en la disputada arena del sindicalismo.

Análisis más recientes han recogido las aportaciones de estos enfoques y han matizado que el comportamiento de los movimientos sociales no obedece a un sólo factor o tipo de factores, ni es tan mecánico. Como han afirmado McAdam, McArthy y Zald (1996: 2-6), la acción colectiva depende de tres factores: las formas de organización, la estructura de oportunidades políticas y los procesos de interpretación y construcción de identidades. Es preciso, por tanto, un enfoque más abierto y sintético (Florido, Roca y Gutiérrez 2013). Y ello requiere de enfoques metodológicos también adecuados, poniendo de manifiesto la vinculación entre los ciclos de movilización social y los ciclos epistemológicos (Calle 2007; Snow y Bendford 1992). Dadas la heterogeneidad, los cambios constantes y las contradicciones internas de los mismos movimientos, las técnicas etnográficas y las historias de vida son acercamientos especialmente necesarios. En particular, la construcción de marcos de referencia por parte de los participantes de los movimientos sociales puede ser aprehendida a través del método biográfico. De este modo es posible acceder a la memoria social compartida, que entra en escena en periodos de crisis social para articular repertorios de acción colectiva. 
Partimos del presupuesto de que la memoria está vinculada a la identidad tanto individual como colectiva. En su dimensión colectiva, la memoria se multiplica de la mano de diversos discursos que se institucionalizan desde el poder, pero también desde los contrapoderes. La construcción de memorias, en plural, por tanto, es la perspectiva de análisis con la que abordamos nuestra investigación. Rastrear en las narrativas de trabajadores y sindicalistas nos da acceso a cómo reconstruyen los episodios de lucha laboral. Qué expectativas tenían los trabajadores, qué motivaciones para participar en las acciones de protesta, para involucrar a sus familias en el movimiento reivindicativo, cuáles eran sus planteamientos respecto a los diseños políticos que los desvinculaban de sus tramas socio-laborales.

No podemos olvidar, por tanto, que todos los discursos de recreación de comunidades por parte de los actores — de la comunidad de trabajadores, de los representantes sindicales, del "pueblo" - actúan sobre un proceso de selección/exclusión, que incluye, y disgrega al mismo tiempo, a pesar de su vocación comunitaria. Porque en todo relato hay protagonistas activos y otros que no lo son tanto, que no lo fueron o cuya participación es silenciada en el discurso que pretende convertirse en hegemónico. La misma política de la memoria de los Estados — no sólo en los regímenes dictatoriales, también en los democráticos-, se despliega activando y desactivando memorias de colectivos y grupos en virtud de consolidar un proyecto común, y eso se desarrolla en diversos niveles y escalas político-administrativas y culturales, desde lo local (Ruiz Ballesteros 2005) a lo supraestatal. Para nuestro estudio, no podemos olvidar que el contexto estructural que sirve de telón de fondo es la última fase de la transición, en la que no tenían cabida aquellos movimientos, ideologías y posicionamientos políticos que no encajaban en el proyecto reformista expresado en los Pactos de la Moncloa (Pérez Serrano 2013).

Este planteamiento nos lleva a tomar en consideración conceptos como los de memoria impedida y olvido o memoria manipulada (Ricoeur 2003). Aquélla es resultado de silenciamientos, de la activación de recuerdos-pantalla de actos y proyectos fallidos, promovidos desde plataformas de poder. En nuestro caso ha sido nuestra intención recuperar un proyecto fallido, el de los obreros y activistas sindicales puertorrealeños que se resistieron con todas sus fuerzas a la dinámica de reconversión, que sí asumieron otras fuerzas sindicales y políticas. De otro lado la memoria manipulada es un resultado colateral del dominio de discursos historiográficos en los que episodios de historia social y sindical, como la que pretendemos elucidar aquí, han atraído menos la atención, el interés y el esfuerzo investigador de los especialistas. No se trata de que desde los ámbitos académicos se haya manipulado los decursos históricos para ocultar acontecimientos, sino más bien de que los procesos de selección de temáticas, de fuentes documentales, de líneas de investigación, etc. han incidido en el olvido de asuntos como el que nos incumbe en este trabajo. Un resultado consecuencia de un proyecto económico y social que pretende imaginar nuevos horizontes para las sociedades afectadas por la reconversión.

Para este trabajo hemos escogido los relatos biográficos de dos sindicalistas del astillero: Juan, de CCOO y Manuel, de CNT. Hemos seleccionado sus testimonios por la riqueza de sus descripciones y, especialmente, porque reflejaban los diferentes discursos y estrategias que cooperaban y rivalizaban dentro del espacio sindical del astillero. 


\section{HISTORIAS DE VIDA DE DOS SINDICALISTAS DEL ASTILLERO}

En 1982 el gobierno español aprobó su segundo decreto de reestructuración de la industria naval. Se sucedieron las protestas y negociaciones por todo el Estado hasta que en 1984 la patronal, la Administración y los sindicatos UGT y ELA-STV (Euskal Langileen Alkartasuna-Solidaridad de Trabajadores Vascos) firmaron el plan de bases para llevarla a cabo mientras que CCOO y la CIG (Confederación Intersindical Gallega) se negaron a suscribirlo. En 1986 una parte de los trabajadores de la factoría en rotación, es decir cobrando una parte del salario pero sin ir a trabajar, decidieron acudir al astillero para manifestar su voluntad de mantener la relación laboral. En enero de 1987 iniciaron las movilizaciones y cortaron con barricadas el puente de acceso a Cádiz, coincidiendo con una visita del heredero al trono de España. Comenzaba así un episodio de protestas, los martes en el astillero y los jueves en el casco urbano de Puerto Real, que duró más de cinco meses. Durante ellos el clima de enfrentamiento con la policía fue ascendiendo hasta que, el 28 de mayo, el Comité de Empresa y la dirección alcanzaron unos acuerdos que pusieron fin a las movilizaciones. Los relatos biográficos de los dos sindicalistas nos narran, primero sus trayectorias vitales, laborales y político-sindicales y, posteriormente, sus visiones y vivencias en torno a este episodio de reconversión.

\subsection{LA VIDA DE JUAN: SACERDOTE, SOLDADOR E IMPULSOR DE LAS COMISIONES OBRERAS}

Juan nació en Jimena de la Frontera (Cádiz). Hijo de militar, se desplazó a Salamanca a estudiar Teología. Había combinado sus estudios con algunos trabajos de verano en la construcción. También emigró una pequeña temporada a Alemania en busca de trabajo. Allí adquirió conciencia de las desigualdades y entró en contacto con los primeros círculos de izquierda. En 1971 entró a trabajar en el astillero sin ninguna experiencia. Afirma que había tal carga de trabajo que al año le "dieron las herramientas", es decir, le ascendieron a oficial de tercera.

Cuando entra en el astillero la hegemonía sindical la ostentaba la USO, con militantes muy formados y provenientes de la Hermandad Obrera de Acción Católica $(\mathrm{HOAC})^{5}$ en buena medida. Las Comisiones Obreras, fuertes en la provincia en otros sectores como el bodeguero o la agricultura, estaban comenzando a despegar en el sector del metal a pesar de estar sufriendo una dura represión con el encarcelamiento de varios dirigentes. Él se afilia a CCOO.

Entonces yo me sentí identificado con la manera de pelear y con la lucha de Comisiones y me metí en CCOO. (...) Y montamos la Sección Sindical en Astilleros de Puerto Real. En contratas éramos muy mayoritarios. (...) Y la UGT no existía en ese momento (Juan, soldador, ex representante del Comité de Empresa por CCOO, entrevista, 17 de septiembre de 2008).

Por aquella época se hace sacerdote y forma parte de la corriente de curas obreros, que estaba muy implantada en la provincia de Cádiz por aquel entonces. A tra-

\footnotetext{
${ }^{5}$ La HOAC es la rama obrera y socialista de la iglesia católica.
} 
vés de CCOO se afilia también al Partido Comunista. Posteriormente se formó la UGT, afirma, gracias al respaldo institucional y al apoyo financiero del PSOE. Cuenta que a finales de los setenta en el astillero una parte de CCOO se escinde para formar la Confederación de Sindicatos Unitarios de Trabajadores (CSUT), ligado al maoísta Partido del Trabajo (que ganó las primeras elecciones en Puerto Real en 1978). Con el tiempo la CSUT desapareció y la mayoría de sus militantes volvieron a CCOO.

A finales de los setenta CCOO tiene la mayoría de delegados en las empresas auxiliares del astillero, donde comienzan su actividad luchando por la integración del personal en la plantilla de Astilleros ${ }^{6}$. En ese contexto CCOO operaba desde dentro del sindicato vertical ${ }^{7}$. Juan fue elegido representante sindical en su contrata y llevaron a cabo importantes luchas, como la negociación del primer convenio colectivo de la pequeña y mediana empresa del metal de la provincia de Cádiz.

Ya desde dentro del sindicato [vertical] forzamos la maquinaria para tener en la comisión negociadora gente de CCOO y entonces convocamos huelga, que era completamente ilegal en ese tiempo. Y desde la dirección del sindicato vertical, que está donde hoy están CCOO y UGT en Cádiz, convocamos a los trabajadores para que fueran allí masivamente a apoyar. Total, hubo huelga. Y hubo presión en la calle. Y los empresarios tuvieron que ceder unas subidas extraordinarias (Juan).

Juan entiende que la construcción del astillero de Puerto Real fue un error del gobierno que benefició a los trabajadores, porque creó muchos puestos de trabajo ante unas expectativas de cargas de trabajo de barcos de gran tonelaje que nunca se cumplieron:

Hubo una crisis mundial fuerte en el año 1973. Los países productores de petróleo empezaron se pusieron de acuerdo por primera vez en la historia y entonces el precio del petróleo se triplicó o se cuadriplicó. (...) Esto coincidió en España con una serie de decisiones, que a nosotros nos vinieron muy bien, pero fueron totalmente equivocadas. Se decidió hacer en Puerto Real un gran astillero para construir barcos, superpetroleros con un millón de toneladas. (...) el cierre del canal de Suez, esta gente lo interpretaron como que harían falta barcos más grandes, porque por el canal de Suez cabe un barco que se llama en Suez Max, o sea, la medida máxima que cabe por el Canal de Suez. El petrolero del millón de toneladas no cabía ahí, pero si aquello se cerraba había que dar toda la vuelta para ir del Golfo Pérsico y venir a Europa o a América, había que rodear toda África. Entonces claro, cuanto más grande fuese el barco, más aprovechabas tú. Más llevabas. Entonces decidieron construir un astillero, el más grande del mundo, y de España y de Europa. No sé si del mundo también. Y lo ubicaron en Puerto Real. Entonces nuestro astillero, que era Matagorda, que era chiquitito pero cuco, y simpático y eficaz, se cerró y se abrió el gran astillero de Puerto Real. A final de la década esa la crisis ya llega a España. En España al final del franquismo y en el franquismo, el sector naval fue un sector muy mimado. Muy mimado, muy apoyado y muy impulsado. Era un poco la joya de la corona. Lo mismo que el Real Madrid era el espejo del régimen en el fútbol, los astilleros eran... En España no se vivía tan mal, había una dictadura y tal, pero aquí se vivía bien y España llegó a ser creo que el tercer país constructor del mundo (Juan).

\footnotetext{
${ }^{6}$ La mayor parte de los trabajadores de las empresas auxiliares en aquella época terminaron integrándose en Astilleros Españoles S.A. a través de este tipo de demandas. Según la legislación de la época, no era posible externalizar actividades que correspondían a la empresa matriz.

${ }^{7}$ El "sindicato vertical" es el nombre con el que se conocía a la Organización Sindical Española, sindicato del régimen franquista cuya afiliación era obligatoria para todos los trabajadores.
} 
Ante el contexto de crisis y en plena transición, en 1978, comienza la primera reconversión, impulsada por el gobierno de la UCD, de la que afirma que fue de la "Salieron mejor parados" debido a la incapacidad del gobierno para aprobar medidas profundas que aumentasen la inestabilidad política y social. En su opinión el gobierno estaba centrado en la transición política y no pudo centrarse en la reforma económica. Así lograron buenas prejubilaciones, bajas incentivadas, e introdujeron una medida que en ese momento no estaba legislada: la "regulación temporal de empleo", esto es la suspensión rotativa y temporal de los puestos de trabajo en lugar del despido. Además, lograron introducir una cláusula en los acuerdos para controlar el "prestamismo laboral" e integrar a los trabajadores de la empresa auxiliar. "Cuando ya empezaron a contratarse barcos después de esta reconversión, que fue poco, pero fue un repunte, pues inmediatamente hubo la integración en plantilla de trabajadores". Poco a poco lograron introducir 1.900 trabajadores en la empresa pública, entre ellos él mismo.

Pero en 1984, con el Partido Socialista en el poder, se produce una nueva reconversión, "más dura", que el gobierno iba a "afrontar con energía". Además, desde su punto de vista, contaba con el apoyo tácito de UGT, que ya había logrado compartir con CCOO la hegemonía del movimiento sindical en toda España ${ }^{8}$, aunque reconoce que posteriormente la reconversión fue el germen de un distanciamiento entre PSOE y UGT.

Aquella reconversión fue muy dura y relativamente rápida. Porque aquí en el país la UGT se puso a favor, a favor disimuladamente, porque claro, no podían dar la razón, pero muy comprensivos con sus hermanos del PSOE y justificaron un poco. Y en frente estábamos los demás (Juan).

UGT es el único sindicato que firma esa reconversión, que se saldó con el cierre del astillero de Euskalduna en el País Vasco, y prejubilaciones y el envío de cientos de trabajadores a fondos de promoción de empleo para ser recolocados en otras empresas.

En 1987 comienza una nueva reconversión. El gobierno actúa, desde su punto de vista, dejando de contratar la construcción de barcos para que los trabajadores perciban que no haya trabajo y cedan posiciones en las negociaciones:

Esta reconversión tampoco dio frutos igual que la anterior. Es que las reconversiones funcionan en que yo te dejo vacío el astillero para que tú te des cuenta de que no hay negocio y después de la lucha y la negociación, para que tú veas que las medidas, y que somos listos, entonces te contratan unos cuantos barquitos y estas unos cuantos años con trabajo. Pero después de tres o cuatro años quieren dar otra vuelta de tuerca. ¿Entiendes? En 1987-88, de nuevo otra vez. Después de esos años de florecimiento, empiezan a no contratar barcos, empezamos a preocuparnos... con la mosca detrás de la oreja. Entonces ya, el libro blanco se había hecho la reconversión industrial lo que se decía, pero ahora lanzan la teoría de la reconversión permanente. Ya no se trata de la reconversión con un documento con una negociación puntual, sino que hay que estar siempre reconvirtiéndose porque la industria es así, porque siempre tenemos que estar adaptándonos al mercado y tal. Entonces hay que ir tomando medidas (Juan).

\footnotetext{
${ }^{8}$ Para análisis completo sobre la trayectoria de UGT en este periodo, ver Vega García (2011).
} 
En esa fecha los trabajadores en los fondos de promoción de empleo no habían logrado recolocaciones y en el astillero no había buenas perspectivas de trabajo. Además, afirma que la UGT ya se había terminado de distanciar respecto al PSOE y fue en ese momento cuando Puerto Real "levantó con más fuerza el hacha de guerra". De este modo deciden en asamblea cortar el puente de acceso a Cádiz como modo de protesta.

Juan afirma que desde el Comité de Empresa - CCOO, UGT y CAT- diseñaron el proceso de movilización. Lo primero fue "cargarse de razones", pedir apoyo de las administraciones y la sociedad locales y luego organizar las protestas.

El diseño nuestro era, lo primero, cargarnos de razones. Es decir, sacar a la opinión pública y entrevistarnos con ayuntamientos, con diputación, con agentes sociales, con asociaciones de vecinos... Gracias a eso conseguimos una manifestación con 100.000 personas en la primera reconversión en Cádiz. Es decir, primero informamos. Notas a la prensa, reunión con el alcalde o alcaldesa de Cádiz. Todo eso publicitado. Asociaciones de vecinos, APAs [Asociaciones de Padres de Alumnos]... Un mes y medio o dos meses explicando: "Tenemos este problema. Necesitamos solidaridad. Pronúnciense a favor nuestro". Y después empezamos a apretar las clavijas. Una vez se ha informado y tal, el gobierno no responde o no se han satisfecho nuestras expectativas. Entonces hay que apretar las clavijas (Juan).

Así estuvieron varios meses de asambleas semanales en la fábrica y en Puerto Real, y posteriormente de movilizaciones que terminaban en duros enfrentamientos con la policía. Juan reconoce que la acción arriesgada de los militantes de CNT, que eran según su visión "ultra radicales", les vino bien para defender sus posiciones en la mesa de negociación.

Hombre, a nosotros nos venía un poco bien. Porque nosotros, quizás los tres [CCOO, UGT y CAT], pecábamos un poco, no sé si decir, de sensatos. No nos gustaba. Nos daba miedo la guerrilla. Y a ellos [CNT] les gustaba organizar la guerrilla (Juan).

Juan recuerda bien los cortes de carretera y los enfrentamientos con la policía:

Entonces íbamos a cortar el puente. La dinámica que iniciamos era esa: nos íbamos a un lado y la policía no podía hacerse la loca. Tenía que ir a desalojarnos allí. Entonces primero fue los martes en el puente, aquello el Ministerio de Interior, Corcuera [ríe] y compañía, empezaron también a utilizar estrategia de lucha contra la kale borroka. Entonces veíamos cosas muy raras. Los que lo veíamos un poco en frío. Yo tenía complejo, yo decía "Yo tenía que ser soldado raso, no como general, que tenía que estar a pié de...". La empresa te llamaba, la prensa, de la radio y dirigiendo un poco la cosa de lejos. Pero la guerrilla era más atractiva, para el que le gusta la guerrilla. No de lejos, teníamos que ir en cabeza, pero cuando ya la cosa se ponía... teníamos una misión, los servicios médicos pendiente. Uno perdió un ojo, otro... en fin. La prensa llamando (Juan).

Apunta cómo en las asambleas decidían acciones arriesgadas como los cortes de carretera y cómo trataban de animarse para superar el miedo de algunos trabajadores:

En las asambleas decidimos ir a cortar el puente, y decíamos: "Señores, que el Comité ha propuesto y hasta la CNT que nos ha criticado, dice que hay que cortar el puente. Todos decimos que hay que cortar el puente. Entonces vamos a levantar la mano los que digan que sí y los que digan que no. Ahora, que si decidimos que si hay que ir. Hay que ir todo el mundo. Aquí no vale escaquearse". Una secretaria se escondía o un grupito de 
gente se escondía intentando escaquearse. Entonces íbamos en culebrina sacando a la gente. Y así muchas veces. El discurso es: "si hay que ir, hay que ir. Cuando nos desalojen, bueno, pues bien, nos han desalojado, es lo que pretendíamos. Ya ha saltado en la opinión pública y tal, no queremos que haya héroes ni que haya heridos, por favor. Que nadie se haga el loco". Y había gente que se ponía a torear a cuerpo descubierto las bolas de goma (Juan).

Tras varios meses y al percibir que la policía iba aprendiendo a controlar los cortes de carretera decidieron sacar el conflicto a la ciudad. Juan relata la emoción de las asambleas populares:

Y empezamos ya los martes en el astillero y los jueves en Puerto Real. Aquí nos iban a comer las moscas. Porque esto está aislado y tal. Y la policía nos echaba ya antes porque le habían cogido el truco. Y la gente se cansaba también, porque la gente se cansaba, menos los que les gusta la guerra de guerrillas. A la gente le daba miedo (...) la policía iba dominado la situación y sabiendo tal. Total, que llegamos a la conclusión de que eso había que sacarlo de allí y ponerlo en la opinión pública por derecho. Entonces convocamos una asamblea un jueves aquí en Puerto Real. En esa asamblea, como en todas las asambleas nuestras, aparte de echarnos todo el discurso para calentar el ambiente y intentar dar los mensajes que queríamos dar en concreto, y apuntar las salidas, que creíamos que el gobierno tenía que ser sensible. Darle contenido. Había otra mucha gente, no sólo CNT, sino mucha gente, incluso mujeres. Y ahí ya, la carga de sentimentalismo, y la carga de emoción era mucho mayor (Juan).

Recuerda que el nivel de enfrentamiento y radicalidad de las acciones fue creciendo hasta que recibieron una llamada de Juan Sáez, Director General del Instituto Nacional de Industria, para buscar una solución:

El Juan Sáez este nos llamó: "Mira, esto está tomando unos niveles. Vamos a vernos". Entonces comenzaron la negociación de los Acuerdos de Jerez. Fue un jueves, lo recuerdo perfectamente, porque ese día estuvimos nosotros al menos hasta las siete de la tarde aquí en Puerto Real. Fue una movida muy gorda. Porque claro, esto iba in crescendo, cada día había que hacer una movida más fuerte que la anterior. Ahora hay que quemar coches. Cada vez una cosa más gorda. Y también hay gente que le había cogido el tranquillo y el gustillo al asunto, no siempre trabajadores de astilleros, y entonces pues diabólicamente intentaban barbaridades más gordas y tal [ríe]. Y entonces estábamos hasta tarde. (...) La dirección que venía de Madrid, claro. Vamos a un sitio neutral. Que esté todo más libre, y más sereno, sin la presión de la gente. Entonces nos fuimos a Jerez. A la Plaza del Caballo, a un local sindical, el local de Comisiones. Nos dieron una llave, nos dejaron una máquina de escribir, nos dejaron una fotocopiadora. Ocho o nueve de la tarde. Nos cominos un bocadillo deprisa y corriendo. Gente de Comisiones, de UGT (...) y de CNT. Los cuatro sindicatos. Había seis de cada grupo, pero de cada grupo nada más que hablaba un portavoz en la mesa. Pero había recesos. Y ellos igual, ellos tenían su despacho, con su contacto directo con Madrid, aunque había venido Sáez Elegido que era el presidente. Y a las dos de la mañana terminamos la negociación y llegamos a un acuerdo (Juan).

Hoy mirando atrás apunta que la reconversión era necesaria para la economía del país, aunque en aquel momento él no pudiera reconocer eso y actuara para suavizarla.

[El gobierno] Tenía su parte de razón, aunque [ríe] en aquel tiempo nosotros no la queríamos reconocer ni se la podíamos dar. Pero 25 años más tarde uno puede decir, tiene su parte de razón y es que España va a entrar en Europa, y España tiene que adaptar su economía a Europa. Nosotros no podíamos (Juan). 
Explica que la forma en que estaba organizada la producción originaba enormes pérdidas al Estado y beneficiaba a bancos, empresarios de la industria auxiliar y trabajadores:

Aquello era un mundo muy corrupto, y muy tal. Cada ingeniero tenía su contrata, entonces... Lo que pasaba en la empresa pública, en el franquismo pasaba y hoy [duda] no pasa como antes, pero pasar también en muchos... pero entonces era casi oficial, o sea, el astillero tiene todas las pérdidas, porque es público, y entonces que pierda papá estado. Porque además en aquel tiempo se podían reponer pérdidas. Anualmente había una reposición de perdidas. Se inyectaba dinero en Astilleros Españoles Sociedad Anónima, con lo cual importaba realmente poco si había muchas pérdidas o pocas. Pero todo el que trabajaba en Astilleros Españoles ganaba dinero, las contratas, los bancos, o sea, todo el mundo ganaba dinero, todo se realizaba de tal manera que todo el mundo ganaba dinero y todas las pérdidas fueran a la empresa pública (Juan).

Explica que la clave de la reconversión, que afectó a varios sectores, fue la entrada en la Unión Europea, que exigía el fin de la protección estatal:

...con el franquismo había una economía muy autárquica, es decir, nosotros... la economía española en el franquismo, y aunque al final del franquismo ya se había abierto tímidamente al mundo, pero no era una economía complementaria con Europa. Aquí fabricábamos nuestros coches, todo, todo. Al entrar en Europa, una de las cosas que te exigen es que: "Oye, tienes que abrir tus fronteras, déjate de proteger tu industria. Nosotros te damos hueco, y te vamos a dar un montón de pasta, pero nosotros queremos acceder a tu mercado y vender nuestras ollas exprés en España, aunque se haga en Italia, o donde sea». Tú no puedes decir que tu olla exprés, aunque sea más cara y más mala... fuera aranceles en la Unión Europea. Entonces Solchaga dice: "Tenemos que reconvertir nuestra industria, hay cosas que debemos dejar de hacerlas, porque es más barato allí que aquí, porque somos ineficaces y somos ineficientes". Mientras han estado protegidos, mientras ha habido aranceles, mientras ha habido fronteras pues hemos sobrevivido, pero ahora, ahora hay que hacer este proceso. Hay que desmantelar la industria. El sector naval hay que renovarlo. La siderurgia, se produjo la guerra de Sagunto, una guerra fuerte. La gama blanca de los electrodomésticos, lo mismo, hay que reestructurarlo (Juan).

\subsection{Formación, trabajo y militancia: La historia de MANuEl, Sindicalista de CNT}

Manuel nació en El Puerto de Santa María (Cádiz) en 1955 en el seno de una familia de mayetos (nombre con el que se conoce localmente a pequeños propietarios campesinos). Desde pequeño trabajó en el campo, así que no fue a la escuela hasta los diez años. Hasta los 13 años fue a la escuela por la mañana y trabajaba en el campo por la tarde. A los 13 años entró en un taller de mecánica, pero le fue mal y volvió al campo. A los 18 se fue a Barcelona a trabajar, luego hizo el servicio militar y finalmente regresó a su ciudad natal, donde se casó y trabajó unos años con transportes ligeros. Entró en el astillero en 1981, en una contrata de limpieza, ya que un cuñado suyo le avisó de que allí hacía falta personal.

Ya durante el servicio militar entró en contacto con las ideas de izquierda. Pero fue en El Puerto donde fue definiendo su orientación política y comenzó la militancia. A través de María, su esposa, entró en contacto con la gente de la parroquia de San José Obrero, que habían creado una Escuela de Cultura Popular. Uno de los cursos 
que más le marcó fue de iniciación al sindicalismo y a las ideologías políticas de Juan Conde, militante de la CNT jerezana y cristiano de base. Ahí empezó a sentirse identificado con el anarquismo. "Cuando este hombre ya nos expuso las ideas anarquistas, empecé yo a verlo como mas fiable, como que los planteamientos eran menos manipuladores y más de fiar". En el astillero se identifica con la CNT oyendo hablar a sus militantes en las asambleas. "Nada más que escuchaba a Pepe Gómez [líder de CNT en la empresa] y escuchaba a los otros, pues ahí no había lugar a dudas". Así, al poco tiempo se afilia a la CNT de Puerto Real.

En 1990 comienza su proceso de integración en la empresa matriz desde la contrata en la que trabajaba:

En el año 1990 se da la circunstancia de que Galeote, el que monta la empresa, y que había sido de la plantilla de astilleros, y era el cabeza de turco, porque allí al parecer había varios ingenieros detrás de eso. Y él es el que monta la empresa, pero había más propietarios. Y entonces Galeote muere. Y ahí no se qué evolución hay, pero parece que Galeote, al final era propietario él solo. El caso es que la empresa era de la familia. Entonces Galeote muere y se queda dirigiendo la empresa el hijo. El hijo era un chaval joven y se queda con la empresa. Está un tiempo, pero ya viene la crisis de 1978, de falta de trabajo. Entonces en 1978 es cuando se da la crisis que dejan de contratar, que no hay trabajo, y estábamos en el proceso ese de rotación, que estábamos un mes trabajando y un mes no. Hubo un tiempo que estábamos dos meses sin trabajar y uno sí. Y en todo este proceso va teniendo cada vez más problemas con la empresa el contratista. El contratista es el que en el desgaste que va teniendo en todo este proceso decide poner la demanda de integración. Entonces como él estaba metido como plantilla, porque ahí los propietarios eran la familia y él estaba como plantilla, de él es la iniciativa de poner la demanda de integración. Entonces él pone un folio encima de la mesa para que firmemos la gente. Y empezamos a firmar todos. Claro, una vez que Comisiones se encuentra con eso, Comisiones se apunta a la lucha por la integración, para no estar contra los trabajadores (Manuel, soldador, militante de CNT en el astillero, entrevista, 4 de julio de 2008).

Inicialmente el abogado de CCOO les había explicado que había un 75\% de posibilidades de ganar la demanda, pero más adelante representantes del sindicato negocian indemnizaciones por despido. En una asamblea de su contrata Manuel se enfrentó al dirigente de CCOO, rechazando indemnizaciones y defendiendo la integración.

Entonces allí fui yo el que me levanté y dije que todo el camino que habíamos andado era por la demanda, que nos habían dicho que teníamos un $75 \%$ como mínimo de posibilidades de integración, y por qué íbamos a negociar a la baja si lo que queríamos era la integración en la plantilla. La mayoría de la gente estaba en esa onda, pero el elemento de Comisiones cogió un cabreo conmigo grande. Recuerdo que me dijo: “¿Tú qué quieres coger a Dios por las patas?". Y yo le argumenté que no quería coger a Dios por las patas, sino la integración (Manuel).

Finalmente ganaron la demanda y se integraron en el astillero. Y una vez dentro les dieron formación para que desarrollaran un oficio. Él aprendió soldadura. Posteriormente, dependiendo de las cargas de trabajo, Manuel ha trabajado conduciendo la ambulancia del botiquín o en maquinas de oxicorte.

Considera que esa primera crisis del sector naval en la que él entró en la plantilla se saldó con la contratación de más trabajadores debido a la vigorosidad del movimiento sindical: 
Yo entré porque ahí hubo una crisis ya con la UCD. Empezó la crisis del sector naval. Entonces ahí hubo una crisis ya de trabajo y eso. Que la resolvieron contratando más trabajo. Pero esa crisis, a diferencia de la que viene con posterioridad, es la crisis en la que los sindicatos están creciendo, están ganando terreno, y están haciendo labor sindical. Entonces hay un proceso de integración, y se van integrando casi todas las contratas (Manuel).

Durante su vida ha tenido una trayectoria militante muy activa en El Puerto de Santa María: primero en la Escuela de Cultura Popular y posteriormente en la Asociación Ecologista Guadalete (que se federa en Ecologistas en Acción) desde donde se oponen a la construcción del puerto deportivo "Puerto Sherry" y fundan la "Marcha a Rota" (contra la base militar estadounidense). También fue muy activo durante un tiempo el movimiento vecinal del municipio, primero en la Coordinadora de EMAS (un tipo de edificaciones catalogadas en el Plan de Ordenación Urbana como "Edificaciones Marginales Aisladas") y después en la asociación de vecinos de su barrio. En 1996 surge la posibilidad de constituir una federación local de CNT en el municipio. Desde entonces ha centrado su militancia en el sindicato, del que ha sido secretario general a nivel local y regional en varias ocasiones.

Manuel recuerda bien los episodios de la reconversión, aunque al ser cíclicos a veces confunde los tiempos en los que ocurrió cada cosa. Afirma que la falta de trabajo es una decisión política, parte de una estrategia del poder político. El detonante de la protesta fue la falta de trabajo:

El antecedente está en el proceso de liberalización de la economía como lo llamaban esta gente. Entonces ya estamos en el proceso de eliminación de la empresa pública. Y lo que ocurre en 1987 es que ya hay una crisis de trabajo. Hay falta de cargas de trabajo. La falta de cargas de trabajo es provocada lógicamente porque ellos quieren, porque no quieren coger trabajo para reducir la empresa pública (Manuel).

Dice que desde el comienzo la postura de $\mathrm{CNT}^{9}$ se diferenció de la del Comité de Empresa, que sí aceptaba los despidos y quería negociar a toda costa.

Ahí salen las dos posturas. La postura del Comité de Empresa y los sindicatos que lo integran, que es de negociar todo. O sea, en el fondo estaban aceptando la crisis, estaban aceptando que algo había que hacer, aceptando los argumentos de la patronal. Entonces su planteamiento era negociar para que fuera lo menos malo para los trabajadores. (...) Mientras que la CNT dice claramente que hay cosas que no son negociables, como el despido de gente. Eso y más cosas, pero que no fuera negociable bajo ningún concepto la baja de la gente.

Y entonces ante la postura del Comité que está negociando, y como está aceptando el excedente de personal. La CNT empieza un proceso de radicalización de la lucha. Básicamente con los argumentos de que ahí hay cosas innegociables, y como la cosa avanza y la empresa mantiene los excedentes y tal, la CNT lo que hace es que ante la imposibilidad de hacer huelga por haber poca carga de trabajo, porque las huelgas ya no son eficaces porque ya Astilleros está con poco trabajo y no le afecta mucho (...) La CNT pues

\footnotetext{
${ }^{9}$ La estrategia sindical de CNT no contempla la participación en los Comités de Empresa por percibirlos como herramientas para la neutralización del conflicto laboral. En cambio, apuestan por las asambleas de trabajadores y las secciones sindicales, que funcionan mediante "democracia directa" y así, aducen, favorecen la participación y la movilización.
} 
la salida que le dio fue crear un conflicto social, ante la imposibilidad de hacer presión con bajo rendimiento, o haciendo huelgas totales. Lo que se hizo fue pensar en el conflicto social (Manuel).

CNT interviene activamente en las asambleas para radicalizar la lucha. Propone que como estaban en rotación ${ }^{10}$ y no había cargas de trabajo, la huelga era inútil. Así que la estrategia fue provocar un conflicto social. Por eso se propuso cortar el Puente Carranza de manera "indefinida aunque intermitente". Los primeros cinco meses la policía no intervino, hasta que desde el Gobierno Civil (hoy Subdelegación del Gobierno) se dio la orden de hacerlo, desde su punto de vista, fruto de un cambio de estrategia por parte de las autoridades. De este modo, comenzaron las barricadas, y los enfrentamientos con tirachinas, botes de humo, balas de goma... La represión fue dura. Las reconversiones en el astillero, recuerda, se saldaron con varias detenciones (Manuel entre ellos) y dos personas que perdieron un ojo.

Entonces se empezó a cortar la carretera. Al principio la estrategia del gobierno fue abrir carreteras alternativas por San Fernando al tráfico. Y hacer como que les daba igual, que no les afectaba. De hecho cinco o seis meses estuvimos cortando la carretera sin que la policía interviniera. La gente ya se aburría, diciendo que eso no valía para nada. Lo que pasa es que nosotros manteníamos que si importaba, que eso era una ilegalidad, que eso no lo podían permitir indefinidamente. Pero que estaban en la estrategia de que nos aburriésemos. Hasta que empezó a intervenir la policía, y empezó la gente a entender que era eficaz. (...) Se montaban barricadas. Se cogían piedras grandes, y de allí del dique se cogían cubiertas para quemarlas, madera, todo lo que se encontraba para que ardiera. Sobre todo al principio, que empezó a primeros de año y hacía frío. Hacíamos una candela grande y nos calentábamos. Y nos calentábamos también subiendo piedras grandes y cosas [ríe]. Si porque además allí había un caño y lo había que cruzar. Se hizo un puente (Manuel).

Manuel recuerda con satisfacción una anécdota en la que la unión y el arrojo de los trabajadores lograron expulsar a la policía de la factoría. Los trabajadores en rotación que cortaban la carretera se habían refugiado dentro de un barco en el astillero acosados por los agentes antidisturbios. Se corrió el rumor de que sus compañeros estaban en apuros, así que todos los trabajadores fueron a su rescate y, pacíficamente, con las manos levantadas, los echaron de la factoría.

Entonces se corrió la voz a los que estaban trabajando, de que la policía nos estaba dando palos, que nos tenía allí rodeados. En fin. Y corrieron la voz y la gente que estaba trabajando se fue para allá. Entonces la policía al ver tanta gente, dejó de tirar. Entonces sacamos a la policía del astillero, diciéndole la gente: "iVete de mi casa! ¡Vete de mi casa! ¡Fuera! ¡Fuera!». Y era la gente avanzando para adelante, y la policía para atrás. Y aquello es largo, más de un kilómetro. Hasta sacarlos del astillero. Estuvo muy bien (Manuel).

Manuel narra cómo sacaron el conflicto de la factoría a través de asambleas en los barrios; cómo el municipio de Puerto Real, que dependía del astillero, también se convirtió en escenario de enfrentamientos entre el pueblo y las fuerzas del Estado. Recuerda los sabotajes, la lucha callejera, los encierros y la "asamblea de mujeres", en la que participó su esposa y que fue severamente reprimida por la policía en algunas ocasiones. Explica así la implicación del pueblo portorrealeño:

${ }^{10}$ Hemos explicado anteriormente que la rotación consistía en una suspensión temporal de empleo percibiendo una parte del salario. 
Puerto Real depende muchísimo de Astilleros. Entonces ahí lo que se planteaba era el cierre de Astilleros, la falta de carga de trabajo. Y eso afectaba a Puerto Real, afectaba al comercio, afectaba a todo. O sea, un pueblo como Puerto Real podía tener 2.000 personas trabajando en el astillero, pues ponlo a 1.000. Y con lo que eso conllevó, eso que se dice que un puesto de trabajo directo en una empresa de éstas, genera siete en el entorno, de servicios y de empresas auxiliares. Pues eso se notaba mucho en Puerto Real. Se estaba notando muchísimo. Entonces hubo un proceso de implicación de mucha gente del pueblo de Puerto Real, y eso pues hizo que hubiese enfrentamientos en Puerto Real que duraban toda la noche, vamos (Manuel).

Los llamados "acuerdos de Jerez", que pusieron fin a ese episodio de lucha, fueron criticados por CNT. Manuel recuerda que en las asambleas para ratificar el acuerdo y finalizar las protestas aparecieron trabajadores que no participaron en las asambleas para organizar la movilización, muchos de ellos de oficina. Estos trabajadores, desde su punto de vista, fueron utilizados por los sindicatos del Comité de Empresa para desmovilizar:

Porque además se da otro elemento ahí. Cuando se trata de la lucha, va la gente más radicalizada. Cuando se trata de votar, ya vienen todos los que no han luchado nunca, que son gente de mono, y sobre todo, gente de oficina. Que no están para ninguna lucha, pero siempre están a la hora de votar para que venga la paz social, para posibilitar la paz social. Entonces con eso es con lo que ellos han contado siempre (Manuel).

A esos trabajadores los llamaron despectivamente una vez "cangrejos" ", y así se les conoce desde entonces. De todos modos, la persona que acuñó ese nombre fue reprobada por no cumplir la norma de no usar descalificaciones a trabajadores en las asambleas. La crítica, en cambio, sólo era legítima hacia la empresa:

[Cangrejos] Así les llamo un compañero que tiene ahora el camping en Vejer. En una asamblea, en el momento en que había una votación. Empezó a llegar gente de la oficina. Pidió la palabra a la asamblea y dice: "Ya vienen ahí los cangrejos". (...) Por lo visto los de Comisiones lo abuchearon. Porque eso, eso de que tu critiques a la gente se ve muy mal. La gente es muy populista, no se le puede criticar. No se puede criticar a un compañero, hay que atacar siempre a la empresa, no a un compañero. Ya puede ser todo lo traidor que sea. Eso lo ve muy mal la gente. Tiene que ser una cosa muy clara... cosas de ese tipo no se le puede criticar a la gente (Manuel).

El desenlace de ese episodio es criticado por Manuel, pues sentó las bases para posteriores reconversiones y el progresivo desmantelamiento de la construcción naval. Desde su punto de vista la medida de las prejubilaciones es la fórmula para conseguir la conformidad de la plantilla contando con la complicidad del Comité de Empresa:

En aquella primera de 1987 se consiguió que el gobierno desistiera de llevar la reestructuración a las bravas. De tirar gente a la calle. Y entonces y allí se sentó el precedente de las prejubilaciones. De ir eliminando mediante prejubilaciones, más cortar la entrada de los aprendices. Entonces con eso se garantizaron que era una cuestión de tiempo. Y han ido contratando, pero creando crisis de cargas de trabajo, para justificar, legalmente un expediente de personal, por tanto, prejubilaciones. Entonces se ha instaurado ya esa

${ }^{11}$ Se trabaja de trazar un paralelismo con los cangrejos, que habitan el entorno del astillero, y viven escondidos entre las rocas o en agujeros en la arena y sólo salen para comer. 
fórmula y la gente encantada. Ahora la gente lo que quiere es que haya más prejubilaciones. Han ido negociando unas condiciones de salida, ganando un buen sueldo, y eso ha hecho que ya la radicalización no tiene cabida. Una radicalización no tiene cabida, porque lo que viene negociando el Comité de Empresa es bueno para la gente. (...) Ahora la gente de la plantilla está mejor que quiere. Con un sueldecito bien. Los encargados son compañeros nuestros. No hay ya gente apretando. No estamos en los trabajos duros. (...) Entonces una radicalización para llevar una lucha fuerte por parte de CNT ya no tiene sentido (Manuel).

\section{ANÁLISIS DE LOS MARCOS A PARTIR DE LOS TESTIMONIOS}

No cabe duda de que el periodo de la reconversión industrial y la transición política, propiciaron una estructura de oportunidades favorable para la acción colectiva (Tarrow 1998). Sin embargo, no basta con conocer el contexto político y socio-económico para explicar este episodio de protesta. La radicalidad y la intensidad de las movilizaciones de Puerto Real, a diferencia de otros lugares, tienen su origen en los marcos o sistemas de significados compartidos por los protagonistas. Los relatos biográficos de los sindicalistas nos permiten rastrear los elementos simbólicos que forman parte de los marcos culturales y las identidades colectivas que entran en juego en la protesta social de los trabajadores del astillero. En toda movilización se produce lo que Snow et al. (1986) denominaron "alineamiento de marco" o enmarcamiento, es decir, el proceso por el cual los intereses y percepciones individuales se conectan con las orientaciones interpretativas, objetivos y acciones de las organizaciones de movimiento social produciendo congruencia y complementariedad. Por ello, los documentos personales son una fuente privilegiada para acceder a dichos marcos. Siguiendo el esquema propuesto por Snow y Benford (1988), nuestro análisis se va a centrar en los tres elementos fundamentales de todo proceso de enmarcamiento: 1) el diagnóstico de los problemas y la asignación de culpa; 2) la elaboración de soluciones y el diseño de tácticas y estrategias para llegar a ellas; y 3) la motivación a los actores para participar en la acción colectiva.

En relación a la identificación de problemas, las narraciones de los informantes son claras: el detonante de la protesta fue la falta de cargas de trabajo y la percepción de que peligraba la continuidad del astillero, del que dependía la economía, no sólo de los trabajadores, sino de todo el municipio. Frente a esto, los relatos de Juan y Manuel también coinciden en la asignación de la culpa. Juan explica que la construcción naval durante el franquismo fue "la joya de la corona", un sector "mimado" e "impulsado" económicamente por el Estado con el objeto de ofrecer una imagen de empleo y prosperidad en ciertos territorios, garantizando así la paz social. Utiliza también la expresión "papá Estado" abundando en esta idea de la economía paternalista, dependiente del Estado, que predominaba en aquella época y que, hoy, reconoce que era "ineficaz e ineficiente" y debía adaptarse al proceso de apertura económica y al nuevo mercado europeo que se estaba configurando. Manuel, por su parte, coincide en la identificación de la liberalización económica como origen del problema. Sin embargo, va más allá al argumentar que la diferencia entre la primera crisis del sector naval que se saldó con mayor protección estatal y la segunda, que marcó el comienzo de la privatización y reconversión, fue el poder social del movimiento obre- 
ro. Desde su visión, un contexto en el que los sindicatos crezcan, "ganen terreno" y desarrollen "labor sindical" es un garante para que las políticas públicas favorezcan el empleo. Por el contrario, se entiende, que un debilitamiento del movimiento sindical hace posible que las políticas de liberalización destruyan empleo. A lo largo de su narración, Manuel diferencia la actitud radical e intransigente de CNT en contraste con el carácter negociador y conciliador del Comité de Empresa. En cierto modo, puede deducirse se considera al Comité de Empresa y a los sindicatos que lo integraban coresponsables del devenir del astillero.

El segundo aspecto a analizar del marco de la protesta es la elaboración de soluciones, estrategias y tácticas ante la amenaza de cierre del astillero. Por un lado, los informantes coincidían en su análisis de la estrategia gubernamental (y desarrollaron la estrategia sindical dialécticamente, en respuesta a la actuación de las autoridades). La primera parte de la estrategia gubernamental consistía en no contratar trabajo para el astillero, para que los trabajadores se fueran mentalizando de la situación. Manuel señala que "la falta de cargas de trabajo es provocada lógicamente porque ellos quieren, porque no quieren coger trabajo para reducir la empresa pública". Juan afirma que "las reconversiones funcionan en que yo te dejo vacío el astillero para que tú te des cuenta de que no hay negocio y después de la lucha y la negociación". La respuesta de los trabajadores a la falta de trabajo era la "lucha". Manuel nos explicaba que en una empresa en la que no hay trabajo la huelga es una táctica ineficaz, por ello, desde su sindicato, propusieron cortar el puente que conecta Cádiz con la Bahía con la intención de crear un "conflicto social". Sin embargo, comentan que la primera reacción de las autoridades fue desviar el tráfico y esperar a que los trabajadores desistieran. La falta de reacción por parte del poder comenzó a desanimar a algunos trabajadores. Con la expresión "nos van a comer las moscas", Juan sintetiza la sensación que tenían algunos de sus compañeros los primeros meses de protesta. Pero todo cambia cuando la policía empieza a intervenir. Según Manuel, esto hizo que la gente "entendiera que era eficaz" lo que se estaba haciendo.

De este modo, se inicia un periodo de enfrentamiento con las fuerzas de seguridad del estado. Los relatos de los sindicalistas están llenos de adjetivos y metáforas bélicas para referirse a estos episodios: "lucha", "guerrilla", "guerra", "barricadas", "hacha de guerra", "enemigo", etc. Además, reconocen que el nivel de violencia fue in crescendo deliberadamente para aumentar la presión sobre las autoridades: "cada día había que hacer una movida más fuerte que la anterior. Ahora hay que quemar coches. Cada vez una cosa más gorda". Otra táctica fue sacar el conflicto del entorno de la factoría para extenderlo al municipio todos los jueves, reproduciendo los cortes de carretera y la lucha callejera. Los trabajadores utilizan metáforas de su entorno laboral para referirse a esta dialéctica entre gobierno y trabajadores: tuvimos que "apretar las clavijas", "el gobierno nos dio otra vuelta de tuerca".

En todo caso, previo a la utilización de métodos violentos de protesta los sindicalistas necesitaron el apoyo y la legitimidad de la sociedad local. Lo que Juan denominaba "cargarse de razones", manteniendo reuniones con los representantes políticos y de la sociedad civil, y realizando asambleas en los espacios públicos del municipio. Estas actividades se corresponden con los que Snow et al. (1986) denominan "extensión de marco", es decir, difusión de los marcos del movimiento social al conjunto de la sociedad local, algo que estaba favorecido por la dependencia de la 
economía del municipio respecto al astillero, y que facilitó la participación de cientos, e incluso miles de personas en las protestas.

El tercer elemento del proceso de enmarcamiento es la motivación de los actores para implicarse en la acción colectiva. De las narraciones de los sindicalistas se extrae que existía una fuerte presión de grupo para que los trabajadores participaran en las acciones directas. Si una medida era aprobada en la asamblea era una obligación participar: Juan afirma que "aquí no vale escaquearse", "si hay que ir, hay que ir". Y que en ocasiones había gente, "una secretaria, o un grupito" (lo cual refleja la importancia de la masculinidad en el marco que justifica esta acción colectiva) que trataba de esconderse y había que sacarlo a través de la "culebrina", una táctica consistente en recorrer con un megáfono todos los talleres paralizando el trabajo y animando a la plantilla a sumarse a la acción que se iba a realizar. Manuel, además, explica que cuando el conflicto se extiende al municipio la interdependencia económica hizo que las asambleas en los barrios incitaran a muchos ciudadanos a sumarse a las protestas, prolongando los enfrentamientos callejeros hasta la madrugada. En efecto, la radicalidad en los métodos de lucha sólo es comprensible desde la legitimidad que gozaban sus protagonistas. Dicha legitimidad procedía, en última instancia, de la fuerte interrelación entre el astillero y la sociedad local, cuya conciencia formaba parte del marco cultural que justificaba la acción colectiva ${ }^{12}$.

Había otro elemento de la cultura del trabajo de los trabajadores del astillero que favorecía la solidaridad y la implicación: existía la norma, que Manuel calificaba de "populista", de no criticar a las personas, sólo a la empresa. El episodio del reproche al sindicalista de CNT que llamó "Cangrejos" a los que aparecían por las asambleas sólo para votar el fin de las protestas ilustra bien esta cuestión. Si, siguiendo a Bauman (2003), la modernización supuso la desmembración de los antiguos lazos de solidaridad moral y social, en nombre de la liberación del individuo y la organización científica del trabajo, el contexto de lucha sindical y de movilización social favoreció la percepción de regeneración comunitaria - lo cual no implica su restitución al nivel de las prácticas sociales ni de la organización social en su conjunto- Es decir, como sostiene De Marinis (2005: 18 y ss.), el proceso de "desconversión social", de transformación de las clásicas relaciones entre Estado y Sociedad —en este caso, la financiación pública del desmantelamiento planificado de un sector industrial—, fue condición para la reinvención de la "comunidad". Así, favoreció la aparición de un horizonte comunitario en la escala local y sobre el tejido emergente de los sindicatos. Éstos, convertidos en agencias relevantes del nuevo proceso de transformación social, crearon las condiciones de reconocimiento colectivo que las empresas (el Mercado) empezaban a desmontar con la necesaria colaboración de la Administración (Estado). El episodio descrito por Manuel en el que la unidad y el arrojo de los trabajadores expulsa a la policía de la factoría al grito de "Fuera de mi casa!", ilustra bien la fuerte identificación de los trabajadores con el astillero y la intensidad de las emociones que entraban en juego. En efecto, las emociones fueron un elemento crucial para el desarrollo de este caso de protesta (Jasper 1998).

\footnotetext{
${ }^{12}$ Como Sofía Pérez de Guzmán (2011) ha puesto de manifiesto, el astillero y la lucha de los trabajadores están presentes en la trama ritual de la zona, tan importante para las identidades locales. En el ritual más significativo de la comarca, el Carnaval, el astillero aparece constantemente reflejado.
} 
Al mismo tiempo, las historias de Juan y Manuel desvelan el contexto de competencia sindical en el que se han desarrollado las relaciones laborales en el astillero desde la transición a la democracia. La mayor división existió entre el sindicalismo libertario de CNT, que abogaba por el asamblearismo radical y la acción directa, y otras organizaciones de trabajadores más moderadas, principalmente CCOO y UGT, cuyas cúpulas habían aceptado las políticas reformistas y el pacto social de los principales partidos políticos durante la transición. El testimonio de Juan, representante de CCOO, por ejemplo, ilustra cómo desde el Comité de Empresa se instrumentalizó la radicalidad de las acciones promovida por CNT en las negociaciones. Pero criticaba el dogmatismo de sus militantes, etiquetándolos de "ultra radicales". Manuel, miembro de CNT, sin embargo, criticaba que CCOO y UGT compartían, en última instancia, los argumentos e intereses del gobierno. El espacio sindical, por tanto, era un espacio dividido, aunque en la cultura del trabajo del astillero imperaba la "unidad" y el "compañerismo" como valor fundamental. Esto hacía posible llevar a cabo una acción colectiva masiva y coordinada, a pesar de los múltiples momentos de enfrentamiento a los que hacían referencia los testimonios orales. En todo caso, para Manuel este tipo de acciones radicales sólo son posibles por parte de trabajadores que desempeñen su empleo en condiciones duras, principalmente manuales: "No hay gente ya apretando. No estamos en los trabajos duros". De ahí, desde su punto de vista, que "una radicalización no tiene ya cabida". Opina que "la gente está encantada" con las prejubilaciones y el tipo de acción moderada que lleva a cabo el Comité de Empresa. La acción sindical de CNT ha perdido, desde su visión, gran parte de su espacio.

\section{CONCLUSIONES}

Este artículo ha analizado, a partir de las historias de vida de dos sindicalistas de CCOO y CNT, la memoria social en torno al proceso de lucha contra la reconversión en el astillero de Puerto Real a mediados de la década de 1980. Lo que aporta la presentación polifónica de distintos relatos contemporáneos, cruzados, sobre una temática común es la relativización de las narrativas personales, la contrastación de puntos de vista, el enriquecimiento de contenidos mediante la complementariedad de planteamientos, valores y narrativas. El resultado es una memoria social, colectiva, pero no homogénea, y entendemos que la mera representación de tales discursos permite una primera aproximación a esa diversidad cultural en un nivel microsocial. Nos da acceso a sujetos sujetados, por recuperar la expresión de Ibáñez (1998), permitiéndonos al mismo tiempo un ejercicio reflexivo que elude al discurso autorreferente de la ciencia occidental positivista.

El uso de los relatos de dos actores de los episodios de lucha-negociación sindical en relación a la reconversión en Puerto Real, en los años ochenta, nos permite apreciar el proceso de enmarcación o "alineamiento de marco" de la acción colectiva. En dicho proceso se han identificado lo que según Snow y Benford (1988) son los tres elementos centrales: 1) el diagnóstico del problema y sus culpables; 2) las soluciones, tácticas y estrategias; y 3) la motivación de los actores sociales para participar en la movilización. Así, a partir de las fuentes orales ha sido posible reconstruir el marco cultural que hizo posible ese radical y dramático episodio de lucha sindical. 
Los trabajadores compartían la preocupación por el futuro de sus puestos de trabajo ante las políticas que estaba ejecutando el gobierno. Apelaron al apoyo de la sociedad local y desplegaron estrategias de protesta, algunas de ellas con altas dosis de violencia y radicalidad: cortes de carretera, barricadas, enfrentamientos y sabotajes. Crearon, tal y como ellos describen, un "conflicto social", con la intención de obtener un poder negociador ante las autoridades. Para llevar a cabo dichas acciones recurrieron a mecanismos de solidaridad y a normas grupales, que garantizaron la participación de buena parte de la plantilla en las acciones, incluso las más arriesgadas, y la implicación de la sociedad local.

Hay que hacer mención, no obstante, a la diversidad de planteamientos al interior de la supuestamente unitaria perspectiva obrera. Las posiciones de cada entidad sindical constituían en sí mismas un marco que nos permite conocer cómo se construían los diversos discursos, a veces antagónicos. Otro aspecto relevante que los relatos de vida permiten aflorar es la tensión entre la perspectiva individual y la perspectiva en tanto que miembros de las organizaciones sindicales. Los relatos pueden reconocer a posteriori qué extremos de sus posiciones no eran plausibles, y cuáles de los contrincantes en la arena sindical y/o política se consideraban razonables. Ello nos debe ayudar a comprender las oquedades entre la dimensión individual y colectiva de la perspectiva de los actores sociales, las líneas de fractura en la presuntamente homogénea memoria colectiva, incluso en episodios caracterizados por un importante grado de intensidad emocional, en los que se ponía en juego la virtualidad de un modo de comprender el entorno laboral y social, la identidad social y personal o cuáles habían de ser las reglas con las que organizar la convivencia en un marco de profundas transformaciones socio-políticas y económicas. Como apunta Pujadas (1992), el material biográfico permite huir de la tipificación de los sujetos como representativos y discernir las diferentes posiciones, sensibilidades y experiencias individuales. No se trata de usar una nueva fuente y una nueva técnica (la historia oral, el método biográfico), sino de acceder a recovecos de la experiencia humana que están vedados a las técnicas de investigación propias de la aproximación positivista convencional.

En definitiva, podemos concluir que la memoria social compartida de la lucha contra la reconversión se va sedimentando en el acervo común, de carácter inmaterial, de Puerto Real y otros municipios de la Bahía de Cádiz. Dicho patrimonio contiene las claves con las que los habitantes de dichas localidades interpretan la realidad y actúan sobre ella. Las historias de vida nos muestran cómo la memoria compartida influye sobre los marcos y los repertorios de acción colectiva. La memoria colectiva desempeña un papel crucial en las identidades socioculturales de los habitantes de Puerto Real y su entorno. Como muestra el caso estudiado, comprender la acción colectiva requiere profundizar en la memoria compartida de sus participantes. La reconversión del sector naval marcó el fin de una época y el principio de otra, pero no cabe duda de que sin el conocimiento de ese periodo de la historia reciente no es posible comprender el porqué y el cómo de importantes problemas actuales de la Bahía de Cádiz como el desempleo masivo y las recientes movilizaciones de los trabajadores desempleados del sector del metal. La historia y el futuro de Cádiz aun siguen ligados al astillero. 


\section{BIBLIOGRAFÍA CITADA}

Bauman, Z. 2003. Comunidad. En busca de seguridad en un mundo hostil. Madrid: Siglo XXI Editores.

Calle, A. 2007. "El estudio del impacto de los movimientos sociales. Una perspectiva global". Revista Española de Investigaciones Sociológicas 120: 133-153.

Castells, M. 2012. Redes de indignación y esperanza. Madrid: Alianza.

Cohen, D. 2007. Tres lecciones sobre la sociedad postindustrial. Buenos Aires: Katz Editores.

De Marinis, P. 2005. "16 comentarios sobre la(s) sociología(s) y la(s) comunidad(es)". Papeles del CEIC 15: 1-39.

Delgado, M. 2012. "La economía andaluza durante las tres últimas décadas. 1981-2011", en J. Hurtado y C. Jiménez (coords.), Andalucía. Identidades culturales y dinámicas sociales: 85-122. Sevilla: Aconcagua.

Espai en Blanc (coord.). 2008. Luchas autónomas en los años setenta. Del antagonismo obrero al malestar social. Madrid: Traficantes de Sueños.

Florido, D., J. L. Gutiérrez y B. Roca. 2009. El pueblo en la calle. Reconversión naval, sindicalismo y protesta popular en el astillero de Puerto Real. Sevilla: Centro de Estudios Andaluces.

Florido, D., B. Roca y J. L. Gutiérrez. 2013. "Tightening the Screws. Autonomy, Collective Action and Violence in Puerto Real during the Second Shipbuilding Restructuring". Anthropological Quarterly 86(3): 861-891.

Giddens, A. 1984. The Constitution of Society. Cambridge: Polity Press.

Ibáñez, J. 1998. El regreso del sujeto. La investigación social de segundo orden. Madrid: Siglo XXI Editores.

Ibáñez, T. 2007. "Ilusión y desencanto en una misma entrega". Polémica 60, marzo 2007.

Jasper, J. M. 1998. "The Emotions of Protest: Affective and Reactive Emotions in and Around Social Movements". Sociological Forum 13: 397-424.

Johnston, H. y J. A. Noakes (eds.). 2005. Frames of Protest: Social Movements and the Framing Perspective. Lanham: Rowman \& Littlefield Publishers.

Lewis, D. 2008. "Using Life-Work Histories in Social Policy Research: The Case of Third Sector/Public Sector Boundary Crossing". Journal of Social Policy 37(4): 559-578.

Martínez Romero, M. F. 1991. La industrialización en Cádiz: sector naval (siglos XIX-XX). Cádiz: Universidad de Cádiz.

McAdam, D. 1994. "Cultura y movimientos sociales", en E. Laraña y J. Gusfield (eds.), Los nuevos movimientos sociales. De la ideología a la identidad: 43-68. Madrid: Centro de Investigaciones Sociológicas.

McAdam, D., J. McCarthy y M. Zald (eds.). 1996. Comparative perspectives on social movements: political opportunities, mobilizing structures and cultural framings. Cambridge: Cambridge University Press.

Melucci, A. 1994. "Asumir un compromiso: identidad y movilización en los movimientos sociales", en M. Revilla (comp.), Movimientos sociales, acción e identidad. Madrid: Siglo XXI.

Moreno Navarro, I. 2002. La globalización y Andalucía. Entre el mercado y la identidad. Sevilla: Mergablum.

Pérez de Guzmán, S. 2011. "La representación social de una actividad productiva como contexto y apoyo a la acción sindical. Los astilleros gaditanos en las coplas de carnaval". Cuadernos de Relaciones Laborales 29(1): 201-225.

Pérez de Guzmán, S. 2012. "Negociación colectiva, acción sindical e intercambio político. Un planteamiento teórico apoyado en el análisis de las relaciones laborales en los astilleros de Cádiz". Papers 97(4): 773-794.

Pérez Serrano, J. 2013. "Orto y ocaso de la izquierda revolucionaria en España (1959-1994)", en R. Quirosa-Cheyrouze (ed.), Las organizaciones políticas en la Transición: 249-291. Madrid: Biblioteca Nueva.

Plummer, K. 1983. Documents of Life: An Introduction to the Problems and Literature of a Humanistic Method. Hemel Hempstead: George Allen \& Unwin.

Pujadas, J. J. 1992. El método biográfico: el uso de las historias de vida en ciencias sociales. Madrid: Centro de Investigaciones Sociológicas. 
Ricoeur, P. 2003. La memoria, la historia, el olvido. Madrid: Editorial Trotta.

Ruiz Ballesteros, E. 2005. "Memoria y conocimiento social", en J. M. Valcuende y S. Narotzky, (coords.), Políticas de la memoria en los sistemas democráticos: Poder, cultura y mercado. Sevilla: Fundación El Monte, Federación de Asociaciones de Antropología del Estado Español y Asociación Andaluza de Antropología.

Scott, J. C. 2004. Los dominados y el arte de la resistencia. Bilbao: Txalaparta.

Snow, D. A., E. B. Rochford, S. K. Worden y R. D. Benford. 1986. "Frame Alignement Process, Micromobilization and Movement Participation". American Sociological Review 51(4): 464-481.

Snow, D. A. y R. D. Benford. 1988. "Ideology, Frame Resonance, and Participant Mobilization", en B. Klandermans, H. Kriesi y S. Tarrow (eds.), From Structure to Action: Social Movement Participation Across Cultures. Greenwich: JAI Press.

Snow, D. A. y R. D. Benford. 1992. "Master frames and cycles of protest", en A. D. Morris y C. M. Mueller (eds.), Frontiers in Social Movement Theory: 133-155. New Haven, Conn.: Yale University Press.

Tarrow, S. 1998. El poder en movimiento. Madrid: Alianza.

Todorov, T. 2000. Los abusos de la memoria. Barcelona: Paidós.

Torres, M. 1998. "The Development of a New Politic: the Autonomous Workers Groups (los Grupos Obreros Autónomos) in Barcelona during the Last Years of Francoism, 1968-1975". International Journal of Iberian Studies 11(1): 85-102.

Vega García, R. 2011. La reconstrucción del sindicalismo en democracia, 1976-1994. Madrid: Siglo XXI Editores.

Ventura, F. 2004. Democracia y Sindicalismo de Estado. Elecciones Sindicales en el área metropolitana de Sevilla. Un estudio antropológico. Madrid: Fundación Anselmo Lorenzo.

Watson, L.C. y M. B. Watson-Franke. 1985. Interpreting Life Histories: An Anthropological Enquiry. New Jersey: Rutgers University Press.

Fecha de recepción: 18 de septiembre de 2014

Fecha de aceptación: 21 de febrero de 2015 